\title{
CÓMO SUPERAR LA LÓGICA DEL ESTADO DE PARTIDOS EN EL TRIBUNAL CONSTITUCIONAL: LA REFORMA DEL ARTÍCULO 159 CE
}

\author{
SUSANA GARCÍA COUSO \\ Letrada del Tribunal Constitucional \\ Profesora Titular de Derecho Constitucional \\ Universidad Rey Juan Carlos
}

SUMARIO.

I. Propuesta de reforma del artículo 159 CE

II. Justificación para la reforma del artículo 159 CE: la recuperación del prestigio y la credibilidad del Tribunal Constitucional

III. Una defensa del modelo de Justicia Constitucional de la Constitución de 1978

IV. La apuesta por la elección política, que no partidista, de los miembros del Tribunal Constitucional

V. La individualización de la designación de los Magistrados como fórmula para superar la lógica del Estado de partidos en el Tribunal Constitucional

VI. Profundización en la opción por una designación más democrática y no sólo política de los Magistrados del Tribunal Constitucional: la reforma de su composición

VII. La cualificación de los designados y su control

VIII. Conclusión

\section{PROPUESTA DE REFORMA DEL ARTÍCULO 159 DE LA CONSTITUCIÓN}

Este trabajo se integra en un número de esta Revista que estudia en forma monográfica posibles reformas de nuestra Constitución vigente. Intentaré demostrar que procede modificar la redacción de los tres primeros apartados del artículo 159 CE y la inclusión de una disposición transitoria, en la siguiente forma: 
Artículo 159

1. El Tribunal Constitucional se compone de nueve miembros nombrados por el Rey; de ellos, cuatro a propuesta del Congreso por mayoría de tres quintos de sus miembros; cuatro a propuesta del Senado, con idéntica mayoría; y uno a propuesta del Consejo General del Poder Judicial.

2. Los miembros del Tribunal Constitucional propuestos por el Congreso y el Senado deberán ser nombrados entre Magistrados y Fiscales, Profesores de Universidad, funcionarios públicos y Abogados, todos ellos juristas de reconocida competencia de más de cuarenta años de edad y con más de quince años de ejercicio profesional. Los miembros propuestos por el Consejo General del Poder Judicial de entre Magistrados y Fiscales deberán contar con más de cuarenta años de edady con más de quince en activo en la carrera judicial o fiscal.

3. Los miembros del Tribunal Constitucional cesarán el día que cumplan setenta años de edad o, en su caso, tras de haber terminado el mandato de nueve años en el ejercicio del cargo desde el día de la toma de posesión, debiéndose proceder a la designación de la vacante por el órgano al que por turno correspondiese. De no proveerse la vacante en el plazo de tres meses desde el cese, el Rey procederá directamente a su designación entre una terna de Magistrados de carrera con más de veinte años de ejercicio profesional presentados por el Consejo del Poder Judicial en Pleno en la forma que determine la Ley Orgánica del Poder Judicial. El plazo se interrumpirá para las Cámaras por el tiempo correspondiente a los periodos intersesiones.

Disposición transitoria

Los miembros que integren el Tribunal Constitucional a la entrada en vigor de la presente reforma cesaran de acuerdo con lo previsto en el artículo 159.3 de la misma. A efectos de la renovación se estará a lo establecido en el apartado primero del citado artículo.

\section{JUSTIFICACIÓN PARA LA REFORMA DEL ARTÍCULO 159 CE: LA RECUPERACIÓN DEL PRESTIGIO Y LA CREDIBILIDAD DEL TRIBUNAL CONSTITUCIONAL}

Nuestro Tribunal Constitucional no es el único que ha sufrido graves situaciones de tensión política con gran impacto en los medios de comunicación ni graves críticas en la doctrina.

Antes de dictarse la Sentencia 262/2009, de 7 de octubre, que anuló la Ley 124/2008, llamada Lodo Alfano ${ }^{1}$, el Tribunal Constitucional italiano fue amenazado por el Senador Humberto Bossi con la «ira del pueblo» ${ }^{2}$ en caso de que se declarase su inconstitucionalidad; en Estados Unidos se llegó a acusar a los cinco Magistrados que — frente

1 La Sentencia 262/2009, de 7 de octubre, declaró inconstitucional la Ley 124/2008, de 23 de julio, sobre suspensión de procesos penales contra altos cargos del Estado, que protegía la situación del Presidente del Consejo de Ministros italiano Silvio Berlusconi. Dicha Sentencia fue precedida de manifiestos críticos contra la Ley (il lodo Alfano) por parte de los ex Presidentes de la Corte constitucional Valerio Onida, Gustavo Zagrebelski y Leopoldo Elia y más de cien catedráticos de Derecho Constitucional; filtraciones a la prensa; y una polémica cena en casa del Magistrado de la Corte Luigi Mazzella con el Magistrado Paolo María Napolitano, el propio Presidente Berlusconi y el Ministro de Justicia Angelino Alfano, promotor de la Ley que luego se declararía inconstitucional, días antes de que se votase la sentencia. Cfr., por todos, GIUPPONI, T. F., «La sentenza sul «Lodo Alfano»: quali prospettive», Quaderni Costituzionali (Rivista italiana di Diritto Costituzionale), 2009, núm. 4, págs. 929 ss. y MORRONE, A., «La sentenza sul «Lodo Alfano»: una risposta tardiva», ibidem, págs. 926 ss. Puede verse también DELGADO RAMOS, D., «El Lodo Alfano: Comentario a la Sentencia 262/2009 de la Corte Costituzionale italiana», Revista de Derecho Político, Mayo-diciembre 2010, págs. 317 a 334.

UNED. Teoría y Realidad Constitucional, núm. 29, 2012, pp. 433-456 
a cuatro- apoyaron la polémica sentencia del caso «Bush v. Gore», de 12 de diciembre de 2000, de haber robado la elección del Presidente de los Estados Unidos ${ }^{3}$.

Sin embargo, la situación de tensión en la que se ha visto inmerso el Tribunal Constitucional español estos últimos años tras dictarse Sentencias ciertamente polémicas como las que resolvieron sobre la constitucionalidad del Estatuto de Cataluña ${ }^{4}$ o la legalidad del partido político Bildus , han llevado a la opinión pública a recomendar incluso la desaparición del citado Tribunal o su fusión con el Tribunal Supremo para pasar a formar una Sala más de éste. No comparto las críticas que pretenden la deslegitimación del Tribunal Constitucional, entiendo que carecen de fundamento. No sólo, como veremos, por tradición constitucional, la opción por la Jurisdicción constitucional sigue siendo la más adecuada.

Nuestro Tribunal ha cumplido acertadamente con su misión y tiene una conformación adecuada a su modelo o arquetipo en la Constitución de 1978. No obstante, ha sido afectado por la lógica del Estado de partidos. La situación de tensión en la que se ha visto inmerso el Tribunal Constitucional especialmente en estos últimos años ha provocado tal desencanto y pérdida de confianza por parte de la ciudadanía, que su restablecimiento será lento y difícil. Se hace precisa, por ello, la introducción de reformas que solventen las dudas que sobre su composición, funcionamiento y, en especial, sobre la independencia de sus miembros se han suscitado. Reformas que hasta el momento no se habían planteado. Ni siquiera en la Consulta que el Gobierno elevó, en el año 2006, al Consejo de Estado sobre la reforma constitucional, y que dio lugar a un extenso Dictamen, se proponía como necesaria modificación alguna del Título IX de la Constitución.

En este trabajo no se intenta encontrar una «fórmula óptima» que dé solución al histórico problema de cómo, a quién y por quién se designan los Magistrados del Tribunal Constitucional. Existen tantas fórmulas como Cortes Constitucionales, y todas ellas pretenden adecuarse a las particularidades de sus respectivos sistemas políticos. Sí de reflexionar y encontrar soluciones al deterioro y pérdida de prestigio de las instituciones que tiene su origen en la intervención de los partidos políticos ${ }^{6}$. Se trata de perfeccionar

2 Las declaraciones a que me refiero fueron recogidas en el Corriere della Sera de 7 de abril de 2009.

3 Cfr., TOOBIN, J., The Nine, Inside the secret world of the Supreme Court, Doubleday, Nueva York, 2007, pág. 176 y ss. Otras Sentencias provocaron incluso amenazas de muerte, o el envío de tartas envenenadas a los Magistrados del Tribunal Supremo, Cfr. TOOBIN, J., op. cit., pág. 250 y ss.

4 STC 31/2010, de 28 de junio. Dicho fallo del Tribunal Constitucional provocó, veinticuatro horas después de dictarse, una manifestación popular en Barcelona en contra de la sentencia del Tribunal Constitucional sobre el Estatuto de Cataluña, encabezada por el presidente de la Generalitat, José Montilla, y el presidente del Parlament, Ernest Benanch, junto a los ex presidentes Jordi Pujol y Pasqual Maragall, y los ex presidentes del Parlament, Heribert Barrera y Joan Rigol. A ella, además, asistieron representantes políticos y sindicales, así como personalidades de la sociedad civil catalana. Vid. BLANCO VALDÉS, R., «El futuro de la Justicia Constitucional en España. Tras la Sentencia sobre el Estatuto catalán», en Claves de la Razón práctica, núm. 212, págs. 12 a 23.

5 STC 62/2011, de 5 de mayo. Sobre la citada Sentencia vid. VÍRGALA FORURIA, E., «Las sentencias del TS y del TC de mayo de 2011 sobre Bildu y las Agrupaciones electorales», REDC, núm. 93, 2011, págs. 307 a 326; y TAJADURA TEJADA, J., «El caso Bildu: un supuesto de extralimitación de funciones del Tribunal Constitucional», REDC, núm. 93, 2011, págs. 327 a 375.

6 Cerrado ya el artículo recibí el núm. 28 de la Revista Teoría y Realidad constitucional, $2^{\circ}$ Semestre de 2011, en la que se hace una encuesta a destacados profesores sobre «La renovación del Tribunal Constitucional» (págs. 13 a 90). Su diagnóstico sobre la situación actual de desprestigio del Tribunal Constitucional y las causas que lo han provocado, y su apuesta por la conservación del sistema de justicia constitucional concentrada coinciden en líneas generales con lo apuntado en el presente artículo. 
el sistema como respuesta a nuevas situaciones y acontecimientos. Como advierte Alzaga Villaamil, «[c]uando las instituciones pierden crédito ante la opinión pública y el juego político se desprestigia ante los ojos del pueblo, eludir buscar las causas mediatas e inmediatas de esa realidad y evitar todo intento reformista puede dar, a medio o largo plazo, pésimos resultados. Es cierto que la gran mayoría de los vicios de la política actual no traen causa de la Constitución. Pero, en ocasiones, la reforma necesaria puede alcanzar a un texto constitucional que no se redactó pensando en un nuevo estado de las cosas» ${ }^{7}$.

\section{UNA DEFENSA DEL MODELO DE JUSTICIA CONSTITUCIONAL DE LA CONSTITUCIÓN DE 1978}

Basta con la relectura del artículo publicado en 1928 por Hans Kelsen, La garantía jurisdiccional de la Constitución (La Justicia Constitucional), para recordar la necesaria existencia de órganos encargados de velar por el cumplimiento de la Constitución, y rechazar las opiniones, como las realizadas por algunos sectores políticos, que defienden su falta de legitimidad para invalidar las leyes aprobadas democráticamente. Clásico debate que en España, en concreto, ya se suscitó a consecuencia de la polémica sobre naturaleza del Tribunal de Garantías de la Segunda República Española. No obstante, y salvo excepciones, dicha dialéctica se entiende superada ${ }^{8}$.

No se debe pensar en la desaparición de cualquier tipo de control sobre las leyes. Sería tanto como negar el principio de superioridad jerárquica de la Constitución. Ni siquiera para el caso de las leyes referendadas, como lo son los Estatutos de Autonomía. Sin embargo, se llegó a proponer a través de la presentación una Proposición de ley de reforma de la Ley Orgánica del Tribunal Constitucional, cuando el Tribunal Constitucional se encontraba conociendo de la constitucionalidad del Estatuto de Autonomía de Cataluña, la limitación de las posibilidades de su control ${ }^{9}$. Las leyes no pueden quedar inmunes al control judicial. Como advierte Rodríguez-Zapata ${ }^{10}$, «[p]rincipio esencial del Derecho pú-

7 ALZAGA VILLAAMIL, O., «Entre el Santo temor a la reforma de la Constitución de 1978 y la conveniencia de pensar en ella», en Entre dos siglos. Reflexiones sobre la democracia española, Alianza Editorial, Fundación Ortega y Gasset y Fundación BBVA, Madrid, págs. 83 y 84.

8 Así lo demuestra el hecho de que las nuevas Constituciones de los países de la Europa Central y Oriental surgidas tras el colapso de los Estados de socialismo real a finales de los años ochenta y principios de los noventa, la de los países latinoamericanos, e incluso africanos y asiáticos, hayan creado Tribunales Constitucionales a imagen y semejanza de los estados europeos occidentales. Como ya opinara L. FAVOREU, Los Tribunales Constitucionales, Ariel, Barcelona 1994, pág. 13, «[n]o se concibe hoy en día un sistema constitucional que no reserve un lugar a esta institución. En este mismo sentido ZAGREBELSKI, G., Principios y votos. El Tribunal Constitucional y la política, traducc. M. Martínez Neira, Trotta, Torino, 2008, pág. 3, destaca que «así como el siglo XIX fue el siglo de los Parlamentos, el siglo XX ha sido el de la justicia constitucional».

9 BOCCGG, Congreso, Serie B, núm. 253-I, de 4 de junio de 2010.

10 RODRÍGUEZ-ZAPATA PÉREZ, J., Teoría y Práctica del Derecho Constitucional, Tecnos, Madrid, 1996, pág. 228. En este sentido, baste recordar lo afirmado en la famosa Sentencia «Marbury versus Madison»: «o la Constitución es la Ley Suprema, que no puede ser variada por medios ordinarios, o está en el nivel de los actos legislativos ordinarios y, como cualquier disposición legislativa, puede ser alterada cuando a la legislatura le plazca alterarla. Si la última proposición de esta última alternativa es cierta, un acto legislativo contrario a la Constitución no es Derecho; si la segunda proposición es la verdadera, las Constituciones escritas son intentos absurdos del pueblo para limitar un poder que por su propia naturaleza es ilimitable». 
blico es el que de la invalidez de un acto debe ser comprobada y declarada expresamente por una autoridad un órgano específico», por ello, «[s]i se afirma que ninguna autoridad constitucional puede controlar la voluntad mayoritaria del pueblo soberano, expresada mediante sus representantes en el Parlamento, se niega la institución de la Justicia constitucional».

Sólo los órganos ajenos al Parlamento pueden actuar como primus inter pares entre las distintas opciones parlamentarias. La Constitución es un pacto que debe ser cumplido también por aquéllos que circunstancialmente cuente con mayoría, incluso absoluta, del Parlamento. El control de constitucionalidad es una fórmula de defensa de la oposición y las minorías, o el pueblo mismo a través de mecanismos como puede ser la interposición de un recurso de amparo que tenga como objeto último la aplicación de una ley que se considera inconstitucional. Es su distanciamiento con la institución sometida a fiscalización, el motivo que hace considerar la necesidad de este tipo de órganos de control; y ello con independencia de que la interpretación de la Constitución que realicen pueda no ser la única ni, incluso, la más adecuada o acertada. En definitiva, el debate sobre la legitimación de los Tribunales Constitucionales es una cuestión de opción entre democracia e imparcialidad. No hay sistemas perfectos sino opciones que se adecuan mejor o peor a la realidad del momento o, simplemente, convencen más.

El sistema de Justicia Constitucional por el que se optó en la Constitución de 1978 ha funcionado correctamente todos estos años. El Tribunal Constitucional así como Jueces y Tribunales han ejercido de forma efectiva su labor de defensa de la Constitución ${ }^{11}$. No parece necesario, pues, desde la perspectiva de la reforma constitucional, un cambio de modelo. Máxime cuando no existen verdaderas diferencias prácticas entre los sistemas de justicia constitucional difuso y concentrado ${ }^{12}$.

En los dos sistemas un único órgano interpreta con carácter «supremo» y de forma «definitiva» la Constitución ${ }^{13}$. En ese sentido, el control de constitucionalidad se puede

11 Explica CAPPELLETTI, M., «¿Renegar de Montesquieu? La expansión y la legitimidad de la "Justicia Constitucional”», REDC, núm. 17, 1986, pág. 12, que la fórmula «justicia constitucional» «se utiliza para indicar que el poder del gobierno está limitado por normas constitucionales y que se han creado procedimientos e instituciones para hacer cumplir esta limitación».

12 En este sentido LA PERGOLA, A., La costituzione espagnola nel trentennale della Costituzione italiana, Bologna, 1978, págs. 12 y ss., entiende que Kelsen no era, al contrario de lo que la doctrina ha mantenido, el defensor de un sistema opuesto al judicial review estadounidense sino que lo que pretendió fue «racionalizar» el modelo norteamericano. Sobre la superación de la yuxtaposición entre el sistema americano y el europeo de control de constitucionalidad de las leyes puede verse: PIZZORUSSO, A., I sistemi di giustizia costituzionale: dai modelli alla prassi, in Quaderni costituzionali, 1982, págs. 521 y ss.; PEGORARO, L., «La Circulación, la Recepción y la Hibridación en la Justicia Constitucional», en Anuario Iberoamericano de Justicia Constitucional, núm. 6, 2002 y «Clasificaciones y modelos de justicia constitucional en la dinámica de los ordenamientos», Revista Iberoamericana de Derecho Procesal Constitucional, núm. 2, 2004; FERNÁNDEZ SEGADO, F., La jurisdicción constitucional ante el siglo XXI. La quiebra de la bipolaridad «sistema americano-sistema europeo-kelseniano» y la búsqueda de nuevas variables explicativas de los sistemas de control de constitucionalidad, Universidad Autónoma Nacional de Méjico, 2004; MEZZETTI, L., «Sistemas y modelos de Justicia Constitucional a los albores del siglo XIX», Revista General de Derecho Público Comparado, núm. 6, enero, 2010.

13 En ambos casos, un único órgano en exclusiva interpreta con carácter supremo la Constitución, imponiendo su criterio no sólo al resto de los operadores jurídicos sino al propio legislador. Sus órganos de control se comportan a modo de legislador negativo y tienen reservado el monopolio del rechazo; si bien mediante mecanismos distintos: el Tribunal Supremo en virtud de la aplicación del principio stare decisis y los Tribunales Constitucionales europeos mediante la declaración de invalidez de la ley con carácter general. Incluso cuando el Tribunal Supremo de los EEUU decide no conocer de ciertos casos y dar por buena la solución otorgada por 
decir que es, en uno y otro, concentrado o centralizado, sin bien la intensidad, magnitud o cualidad de la intervención de Jueces y Tribunales en él, se muestra distinta en función del modelo escogido ${ }^{14}$ : europeo o norteamericano. Y, en ambos, los integrantes de los órganos que ejercen el control son nombrados «políticamente». Todo ello básicamente por dos razones: la subsistencia del carácter democrático de un órgano que va a controlar la actuación del legislador y la defensa de la seguridad jurídica. Poco importa, pues, que sea una Corte Suprema o un Tribunal Constitucional.

El verdadero cambio se produciría de modificarse la designación política de los integrantes de los Tribunales a los que, con carácter «supremo» y de forma «definitiva», se les encomienda la función de velar de manera centralizada por el cumplimiento de sus Constituciones. La dicotomía responde a la diferente naturaleza de su procedencia, pues un modelo difuso puro no parece viable. La centralización del control judicial de constitucionalidad se muestra siempre, en palabras de Kelsen, «deseable en interés de la autoridad de la Constitución» ${ }^{15}$.

\section{UNA APUESTA POR LA ELECCIÓN POLÍTICA, QUE NO PARTIDISTA, DE LOS MIEMBROS DEL TRIBUNAL CONSTITUCIONAL}

La opción por la Jurisdicción constitucional concentrada, en el sentido ya expuesto: existencia de un órgano específico que con carácter «supremo» y de forma «definitiva» ejerce el control de constitucionalidad, sigue mostrándose la más adecuada especialmente por el contenido democrático derivado de la elección de los miembros del Tribunal Constitucional. Sólo la falta de legitimación que denuncian aquellos que entienden que no cabe la imposición de criterio alguno sobre el legislador, puede ser, en cierta medida, paliada si la elección de quienes van a contar con dicha capacidad compete a órganos que ostentan representación popular.

La preferencia por un sistema en el que los miembros de los órganos encargados de velar por la defensa de la Constitución son nombrados por órganos de carácter político,

los Jueces y Tribunales ordinarios, está actuando como tal. Los dos comparten también la convicción de la necesidad de preservar el principio de superioridad de la Constitución. Parten de la misma premisa: el sometimiento de los poderes públicos al principio de supremacía constitucional (defensa difusa de la Constitución). Y tienen la misma finalidad última: expulsión o inaplicación, con carácter general, de las leyes como producto del legislador (defensa concentrada de la Constitución). Conclusiones a las que llegaron ambos sistemas, si bien tras sufrir trayectorias vitales distintas. Las diferencias entre ambos sistemas no afectan al núcleo esencial del control de constitucionalidad, sino al tipo de procedimiento que es necesario seguir para alcanzarlo y sus efectos y al sujeto al que se encomienda ejercerlo.

14 En Europa, fue el recelo al Poder Judicial lo que impulsó, entre otras razones, la creación ex novo de un órgano autónomo de control de la constitucionalidad de las leyes: los Tribunales Constitucionales, cuando en EEUU el control surgió precisamente del dictado, por un órgano judicial, de la famosa Sentencia Marbury vs. Madison.

15 Citado por FERRERES COMELLA, V., «Integración europea y crisis del modelo centralizado de Justicia constitucional», Revista Vasca de Administración Pública, núm. 65, nota núm. 4. Dicho autor ha realizado un estudio sobre las virtudes del modelo concentrado de constitucionalidad que puede verse en Una defensa del modelo europeo de control de constitucionalidad, Marcial Pons, 2011.

16 Según informó Europa Press el día 2 de diciembre de 2011, el Magistrado de la Audiencia Nacional, Eloy Velasco, en el marco de las jornadas «La situación de la Justicia en España: diagnóstico y posibles solu- 
impregna, aunque sea indirectamente, del valor democrático del que carecen, por ejemplo, aquellos en los que el ejercicio de la Justicia Constitucional se atribuye de forma única y última a Jueces y Magistrados de carrera, y proporciona la legitimidad que necesita un órgano que, a través de sus decisiones, va a ejercer una labor de dirección política indudable.

No faltan voces que apuestan, sin embargo, por la desaparición de un Tribunal compuesto por miembros de procedencia política defendiendo que sea una Sala del Tribunal Supremo la que se ocupe de los temas constitucionales ${ }^{16}$. Este tipo de propuestas que sostienen reducir el Tribunal Constitucional al Tribunal Supremo darían un peso incompatible con el Estado democrático a un Poder Judicial formado por personas que han accedido a su cargo por oposición frente a la representación democrática del pueblo ${ }^{17}$.

Pero, además, ¿por qué considerar que los Jueces harán una interpretación más adecuada de la Constitución que la que harían otros miembros de diferente procedencia profesional? o ¿por qué pensar que un órgano compuesto únicamente por Jueces de carrera es más independiente en el ejercicio de su función?

$\mathrm{La}$ «independencia» ${ }^{18}$, condición inexcusable para el ejercicio de la Justicia, es difícil de controlar por depender más de la virtud personal que de límites externos. Radica en la conciencia del Magistrado y no puede ser impuesta mecánicamente por la técnica del legislador ${ }^{19}$. La «ingeniería constitucional» poco puede hacer frente a la falta de voluntad. Dicho esto es necesario puntualizar que, la mayoría de las veces, la desconfianza y el recelo sobre la «imparcialidad $»^{20}$ de los integrantes de las instituciones provienen más de la capacidad de influencia que se intuye o presupone de los partidos políticos, que de su actuación: ¿Cómo se entiende sino que la independencia que se presume de un Magistrado del Tribunal Supremo se pierda al llegar al Constitucional?

ciones», celebradas en el Colegio Notarial de Madrid, manifestó «urgente» que el Tribunal Constitucional acabe convirtiéndose en una sexta sala del Tribunal Supremo con el fin de evitar que sea «una tercera instancia» como ocurre actualmente. Según la información, el Magistrado abogó por emprender una reforma constitucional que facilite la creación de una Sala en el Supremo encargada de resolver la impugnación de leyes, las cuestiones de constitucionalidad y los conflictos de competencias. Y explicó que, a su juicio, el resto de salas que integran el Tribunal Supremo deben ser «el máximo intérprete» de la Constitución en las cuestiones relativas a los derechos fundamentales que afectan a cada jurisdicción y con posibilidad de que un recurso para la unificación de doctrina resuelva las divergencias que pudieran surgir entre ellas.

17 A mi entender, en ese sentido se expresa ZAGREBELSKI, G., Principios y votos..., op. cit., pág. 51, cuando en relación con el significado del origen tripartito de los jueces constitucionales italianos, considera que es preferible a la expresión de los tres poderes la de tres lógicas distintas: política para el Parlamento, institucional unitaria para el Jefe del Estado y judicial. Subraya que en la polémica debe concluirse que ha parecido oportuno excluir a los jueces ordinarios del control de las leyes y conceder, en cambio, un privilegio al legislador que debe ser controlado en la elección de quienes deben controlarle.

18 Definida en su tercera acepción por la Real Academia de Lengua Española (en adelante, RAE) como «Entereza, firmeza de carácter».

19 LA PERGOLA, A., La costituzione espagnola..., op. cit., págs. 12 y ss. Como afirma ZAGREBELSKY, G., Principios y votos..., op. cit., pág. 92: «En general, no hay nada más penoso que las personas que han tenido mucho, quizá demasiado, pero que quieren todavía más y así se exponen a indecorosas manifestaciones serviles y cortesanas en sus relaciones con aquellos que piensan que pueden serles útiles».

20 Definida por la RAE como «Falta de designio anticipado o de prevención en favor o en contra de alguien o algo, que permite juzgar o proceder con rectitud». 
En nuestro ordenamiento no todos los integrantes del Poder Judicial son Jueces y Magistrados de carrera, y no por ello se debe deducir más o menos independencia en el ejercicio de la función jurisdiccional, o una mejor o peor aplicación del Derecho. Por el contrario, un repaso de la forma de elección de los Jueces integrantes de las Cortes Constitucionales nos demuestra que su designación proviene, casi en la totalidad de los sistemas, de órganos de carácter político ${ }^{21}$. En Estados Unidos, por ejemplo, no sólo son elegidos por el Presidente sino que no se teme por el carácter político de sus integrantes llegándose incluso a elegir Senadores ${ }^{22}$. Zagrebelski se pregunta en este sentido si «contra el riesgo de politización, ¿se debe buscar para el Tribunal Constitucional un jurista desconocido, sin personalidad y de segunda fila? ¿Encontraríamos en él un antídoto frente a la politización del Tribunal?». Y, con razón, manifiesta que «[c]iertamente no. Al contrario, es importante que los llamados al cargo de juez constitucional tengan una fuerte personalidad y una trayectoria profesional digna que merezca ser reivindicada y defendida. Las medias figuras, los tibios, los Nicodemos que no manifiestan sus ideas con claridad, constituyen un grupo de los que siempre están dispuestos, como se dice, a 'cambiar de chaqueta' según sople el tiempo. No aportan ninguna garantía de independencia, hayan tenido o no en el pasado una experiencia política que defender. Son precisamente ellos, las personas no comprometidas, las que al no ser fieles a sus principios cambian con mayor facilidad de fidelidades $»^{23}$.

Designación política no es lo mismo que designación partidista. La primera se muestra coherente con el sistema democrático, sobre todo en relación con los Tribunales Constitucionales dada la función que desempeñan. La segunda, sin embargo, rompe con él por no responder al parecer de la mayoría y, por ende, al interés general, sino al de la propia formación política que designa, cuyos criterios de decisión responden también a parámetros particulares como lo son el de la «conveniencia» y la «oportunidad». Con una selección de los candidatos realizada desde los partidos políticos se corre el riesgo de confundir el «criterio político» de los nombrados con el «partidismo» entendido como «adhesión o sometimiento a las opiniones de un partido con preferencia a los intereses generales» ${ }^{24}$. Afinidad de pensamiento y partidismo no son lo mismo.

$21 \mathrm{Al}$ respecto de las diferentes fórmulas de designación, puede verse: FAVOREU, L., Los Tribunales Constitucionales, Ariel, Barcelona 1994; servicio de estudios, biblioteca y documentación del Tribunal Constitucional, «Modelos de renovación personal de Tribunales Constitucionales», Revista Española de Derecho Constitucional, núm. 61, 2001, págs. 2009 a 237; TORRES PÉREZ, M., y FLORES JUBERÍAS, C., «Materiales para un estudio comparado de la justicia constitucional en la Europa Central y Oriental», en Cuadernos Constitucionales de la Cátedra Fadrique Furió Ceriol, núm. 20/21, Valencia, 1997, págs. 231 a 264; BREWER-CARÍAS, A.R., «The question of legitimacy: How to choose the Judges of the Supreme Court? The European doctrine and Latin-American contrast, en The future of the European Judicial System in a Comparative Perspective, 6th International ECLN-Colloquium/IALC Round Table Berlin, 2-2 November 2005, Nomos, págs. 153 a 182; KÜHN, Z., KYSELA, J., «Nomination of Constitutional Justicies in Post-Communist Countries: Trial, Error, Conflict in the Czech Republic», en European Costitutional law revew, núm.2, 2006, págs. 183 a 208; FERNÁNDEZ RODRÍGUEZ, J.J., La Justicia constitucional europea en el siglo XXI, Tecnos, Madrid, 2007.

22 Sobre la elección de los Magistrados del Tribunal Supremo de los Estados Unidos puede verse: TOOBIN, J., The Nine, op. cit.; BAUN, J., El Tribunal Supremo de los Estados Unidos de América, Librería Bosch, 1987; y DAVIS, R., Electing Justice (Fixing the Supreme Court Nomination Process), Oxford University Press, 2005.

23 ZAGREBELSKY, G., Principios y votos..., op. cit., pág. 58 y 59.

24 Definición dada por la RAE. 
En nuestro sistema puede apreciarse sin dificultad que aunque técnicamente la designación de los Magistrados del Tribunal Constitucional responde a la intervención de los tres Poderes del Estado, lo cierto que es que el actual sistema hace que, en realidad, sean los partidos políticos, en concreto los mayoritarios, los verdaderos encargados de la elección. Elección política y elección partidista se entremezclan provocando un daño inmenso en la imagen de un Tribunal, como lo es el Constitucional, que, precisamente, por su función, debe quedar al margen de la lucha partidista.

Romper con la participación de los partidos políticos en la designación de los Magistrados del Tribunal Constitucional pasa por terminar con el sistema que vicia desde el inicio la elección, en principio democrática, de sus miembros: el reparto de cuotas, como así ha denunciado la doctrina ${ }^{25}$. Práctica que se hace especialmente evidente en los nombramientos de los Magistrados de procedencia parlamentaria y que ha pervertido lo que entiendo fue la intención del constituyente de 1978: una designación de los Magistrados del Tribunal Constitucional política que no partidista ${ }^{26}$. En realidad, los Grupos parlamentarios, especialmente mayoritarios, no buscan el consenso respecto de cada uno de los candidatos designados, sino que, a través de sus Portavoces, negocian hasta conseguir que sean aceptados los por ellos propuestos, a sabiendas de que, posteriormente, las listas consensuadas recibirán el apoyo en las Cámaras requerido legalmente. Así parece haber ocurrido desde las primeras designaciones ${ }^{27}$.

Que los partidos políticos mayoritarios renuncien al sistema que más les favorece se muestra difícil, pero conviene articular fórmulas dirigidas a limitar, en la medida de lo posible, su intervención en un órgano cuya función se centra en resolver entre lo que la mayoría parlamentaria ha decidido y la minoría ha impugnado, cuando sus sentencias tienen una repercusión importantísima en la dirección política del país. Reconocida constitucionalmente la necesaria participación de los partidos en la vida política, se debe ahondar en su control, y así, desde el manteniendo del espíritu constituyente de profundización en su democratización, fortalecer al mismo tiempo la independencia e imparcialidad de los miembros de las instituciones a través de mecanismos que desactiven o cuando menos dificulten su influencia.

25 También se ha puesto de manifiesto y criticado por RUBIO LLORENTE, F., La forma del Poder (Estudios sobre la Constitución), CEC, Madrid, 1997, pág. 413; FERNÁNDEZ SEGADO, F., «Artículo 159 (La Composición del Tribunal Constitucional)», en Comentarios a la Constitución Española, dir. O. Alzaga Villaamil, Tomo XII, Cortes Generales-Editoriales de Derecho Reunidas, Madrid, 1999, págs. 91 a 94; O. ALZAGA VILLAAMIL, «Sobre la composición del Tribunal Constitucional», en Teoría y realidad Constitucional, núms. 10-11, $2^{\circ}$ Semestre 2002-1 Semestre 2003, págs. 173 a 180, quien ha calificado el reparto de cuotas de «[d]iscutible práctica viciosa con precedentes en la política italiana y alemana, aunque en nuestros lares hemos lograda potenciarla hasta cuotas insuperables», en «El consenso (del proceso constituyente a las prácticas postconstitucionales), en Teoría y Realidad Constitucional, núm. 25, 2010, pág. 124; y en Derecho Político Español, Ramón Areces, $4^{a}$ ed., Madrid, 2008, págs. 700 a 704; GARCÍA MARTÍNEZ, M.A., «¿Quis custodiet custodet? El Tribunal Constitucional y la garantía del orden constitucional», en Indret, octubre 2008, pág. 12; ÁLVAREZ CONDE, E., Curso de Derecho Constitucional, Tecnos, 6a ed., Madrid, 2008, pág. 369; y RODRÍGUEZ-ZAPATA PÉREZ, J., Teoría y Práctica del Derecho Constitucional, Tecnos, Madrid, 2011, 2ª ed., pág. 279.

26 En el mismo sentido ALZAGA VILLAAMIL, O., «Sobre la composición del Tribunal Constitucional», op. cit., pág. 178, entiende que este tipo de comportamientos desfiguran la voluntad inicial del constituyente de 1978

27 Tal y como parece desprenderse de la narración de las primeras designaciones de los Magistrados del Tribunal Constitucional, que hace RUBIO LLORENTE, F., La forma del Poder (Estudios sobre la Constitución), op. cit., págs. 411 a 413. 
Se ha propuesto desde algunos sectores doctrinales elevar la mayoría exigida en la designación ${ }^{28}$. Sin embargo, su aumento no termina con el sistema de cuotas ${ }^{29}$. El reparto de las vacantes seguiría produciéndose, pero se formalizaría en las Cámaras a través de una mayoría superior que podría dificultar el consenso, postergar su designación y provocar las indeseadas dilaciones en los nombramientos.

Otra de las soluciones apuntadas por la doctrina ha consistido en «desvincular la designación de la regla de la renovación por terceras partes cada tres años» ${ }^{30}$. Explica Rubio Llorente que «[a]unque es evidente que en la democracia de partidos, que es la única posible, la designación de los Magistrados del Tribunal Constitucional, como la de los componentes de cualquier órgano semejante, será siempre objeto de negociación entre aquéllos y que tal negociación producirá frecuentemente un retraso en la decisión y se saldará con un reparto de los puestos a cubrir, también es evidente que el riesgo de que suceda lo uno y lo otro es tanto mayor cuanto más rígida sea la periodicidad y mayor el número de Magistrados a designar. La sustitución del procedimiento de las renovaciones periódicas por terceras partes por el de los nombramientos escalonados en el tiempo, no sólo es más respetuosa con el principio cardinal de la duración igual de los mandatos, sino también menos propicia a lo que en Italia se llama "lotizzazione", el reparto del botín» ${ }^{31}$.

Una propuesta interesante que necesita de reflexión y desarrollo.

\section{LA INDIVIDUALIZACIÓN DE LA DESIGNACIÓN DE LOS MAGISTRADOS COMO FÓRMULA PARA SUPERAR LA LÓGICA DEL ESTADO DE PARTIDOS EN EL TRIBUNAL CONSTITUCIONAL}

El paso del tiempo ha puesto en evidencia que el establecimiento de garantías asumidas por los sistemas que han optado por la jurisdicción constitucional concentrada - como la exigencia de mayorías cualificadas, la fijación de un periodo largo para el desempeño del cargo, la renovación parcial, la cualificación requerida a los aspirantes y la imposibilidad de reelección inmediata de los Magistrados-, no ha conseguido frenar el reparto partidario de las vacantes del Tribunal Constitucional. Esta nueva práctica necesita también de una nueva solución que se sume al resto de las garantías enunciadas.

28 FERNÁNDEZ SEGADO, F., «Artículo 159 (...)», op. cit., pág. 98, propone la mayoría de 2/3 como el sistema de elección alemán.

29 En este sentido GARCÍA MARTÍNEZ, M.A., «¿Quis custodiet custodet?...», op. cit., pág. 12, afirma: «La vinculación, si no jurídica sí real, entre partidos y grupos parlamentarios hace que la pieza clave del sistema de designación de los candidatos al Tribunal Constitucional sea la negociación previa y no la mayoría cualificada exigida, que se convierten un simple cálculo aritmético. Por ello no creemos efectiva la propuesta que se ha hecho en alguna ocasión de elevar la mayoría exigida para que puedan prosperar los nombramientos que corresponden a las cámaras parlamentarias (OLLERO, C., 1986, pp. 191 a 194) ya que la razón del sistema de cupos está en la misma estructura de dichas cámaras y no en la mayoría concreta exigida».

30 Planteada por FERNÁNDEZ FARRERES, G., VVAA, La Jurisdicción Constitucional en España (La Ley Orgánica del Tribunal Constitucional: 1979-1994), TC-CEC, 1995, pág. 63; y reiterada en «Reflexiones sobre el futuro de la justicia constitucional española», en El futuro de la justicia constitucional, Actas de las XII Jornadas de las Asociación de Letrados del Tribunal Constitucional, TC-CEPC, Madrid, 2007, pág. 59.

31 RUBIO LLORENTE, F., «El Tribunal Constitucional», REDC, núm. 24, 2004, pág. 16. 
Nuestra Constitución optó, al igual que otros ordenamientos en los que se prevé un mandato de duración limitada, por un sistema de renovación parcial del colegio ${ }^{32}$. Su sustitución por un modelo basado en la individualización de la designación de cada candidato puede dar solución al problema que plantea el reparto de cuotas y recobrar el sentido del consenso por el que considero, como ya he puesto de manifiesto, apostó inicialmente el constituyente de 1978.

Con la renovación individual del Magistrado se obliga a los órganos proponentes al consenso sobre la idoneidad de cada uno de los Magistrados que integrarán el Tribunal; se anula la existencia de cuotas y, por ende, la posibilidad de reparto. Desaparece, igualmente, la apariencia ab initio de parcialidad del Magistrado designado y se pone fin a la práctica, tan en boga estos últimos años, de identificar a los Magistrados por su procedencia conservadora o progresista. Situación que, como explica Zagrebelsky, provoca «cierta incomodidad ${ }^{33}$ entre los jueces «conscientes de su posición institucional cuando la solución de un caso constitucional coincide con la exigida en su propio interés por un partido político (en mayoría o minoría, eso no importa): incomodidad que deriva del riesgo de confusión entre los dos distintos órdenes de razones, las de garantía de la Constitución y las de enfrentamiento político» ${ }^{34}$. Y se relativizan no sólo las aspiraciones de los candidatos y las de aquellos que son nombrados ${ }^{35}$, pues su nombramiento no dependerá de un partido político determinado, sino también las de las propias fuerzas políticas al ver mermada su capacidad de influencia.

En definitiva, el peligro de la dependencia partidista de sus miembros y la pérdida de confianza de los ciudadanos a la que se enfrenta la Institución, queda resuelta, y el sistema de elección queda convertido en un sistema verdaderamente democrático y no sólo político.

Pero, ¿cómo articular el procedimiento de designación para conseguir que las vacantes de Magistrados constitucionales se cubran en momentos diferentes de forma tal que al no existir coincidencia se obligue al consenso sobre la idoneidad de cada candidato? Sólo aquellas causas de finalización del mandato que afecten singularmente a cada uno de los Magistrados designados, permitirá una renovación personalizada de los mismos. Se debe favorecer la individualización de la designación para desarticular el nombramiento conjunto de Magistrados y, por ende, el reparto de las designaciones. Se trata de invertir, como Fernández Farreres plantea, la preeminencia de la regla de la renovación por terceras partes cada tres años, por la garantía del cumplimiento del mandato

32 Art. 159.3 de la Constitución: «Los miembros del Tribunal Constitucional serán designados por un período de nueve años y se renovarán por terceras partes cada tres».

33 ZAGREBELSKY, G.,Principios y votos..., op. cit., pág. 57.

34 Ibidem.

35 Se pregunta ZAGREBELSKY, G., Principios y votos..., op. cit., pág. 92: ¿Qué no se haría por el temor a perder y la esperanza de obtener ventajas? Y ¿no es más fácil que las ventajas sean recompensas? Y ¿las recompensas no exigen comportamientos meritorios a los ojos de las que las puedan repartir? Esta es la tentación que inevitablemente se manifiesta cuando los nueve años del Tribunal Constitucional son subjetivamente vividos como etapa intermedia de una ambición más grande, cuya realización depende de poderes externos que la que pueden tanto promover como obstaculizar o condicionar». Y añade: «No hay nada más penoso que las personas que han tenido mucho, quizá demasiado, pero quieren todavía más y así se exponen a indecorosas manifestaciones serviles y cortesanas en sus relaciones con aquellos que piensan pueden serles útiles». 
de nueve años ${ }^{36}$, «de manera tal que la selección en bloque de cuatro magistrados se fuera diluyendo con el tiempo» ${ }^{37}$. Precisamente en sentido contrario a lo dispuesto en la última reforma de la LOTC operada por Ley Orgánica 8/2010, de 4 de noviembre, por la que se introdujo un nuevo apartado quinto al artículo 16 que establece que «Si hubiese retraso en la renovación por tercios de los Magistrados, a los nuevos que fuesen designados se les restará del mandato el tiempo de retraso en el renovación». Cambiar el sistema actual derivado del modelo italiano, por el de otros países europeos en los que la, en definitiva, renovación es periódica ${ }^{38}$ pero no grupal.

En Austria y Bélgica, por ejemplo, es la fecha de jubilación la que determina el fin del mandato del Magistrado, lo cual personaliza la designación ${ }^{39}$. Así sucede en nuestro ordenamiento con los Magistrados del Tribunal Supremo. Esta fórmula que rompe el sistema de cuotas, termina igualmente con una de las bondades de nuestro sistema actual: la rotación fluida de los miembros del Tribunal Constitucional. Es por ello que no parezca adecuado inclinarse, con más razón, por un sistema en el que los Magistrados ostenten el cargo con carácter vitalicio, como ocurre en el Tribunal Supremo de los Estados Unidos o en Australia, pues con la concesión a los Magistrados de una legitimidad ilimitada en el tiempo, la institución pierde su carácter democrático y se desvincula del sentir de la ciudadanía.

El efecto derivado de la opción por un periodo largo de mandato puede relativizarse con el aumento de la edad mínima de acceso a la condición de Magistrado. Se conjuga, de esta forma, la individualización de la designación con la renovación periódica de los miembros del Tribunal Constitucional, y, al mismo tiempo, se da continuidad a la jurisprudencia constitucional y se refuerza el requisito de la experiencia ${ }^{40}$, de manera tal

36 FERNÁNDEZ FARRERES, G., «Reflexiones sobre el futuro de la justicia constitucional española», op. cit., pág. 5. El citado autor entiende necesario un sistema que apueste por el cumplimiento total del periodo de mandato de los Magistrados nombrados, sin que proceda el descuento del tiempo que se hubiera retrasado la nueva designación. En el sentido de que todos los Magistrados cumplan el mismo periodo de mandato, vid. RUBIO LLORENTE, F., «El Tribunal Constitucional», op. cit., pág. 16.

37 FERNÁNDEZ FARRERES, G., «Reflexiones sobre el futuro...», op. cit., pág. 60.

38 Vid. MANGIA, A., "La durata del mandato dei giudici costituzionali», en La composizione della Corte Costituzionale (Situazione italiana ed esperienze straniere), Atti del Seminario di Roma del 14 de marzo 2003, a cura di A. Anzon, G. Azzaritti, M. Luciani, Giappichelli Editore, Torino, 2004, pág. 129. El citado autor esquematiza la duración del mandato de los Magistrados de Tribunales Constitucionales en cuatro modelos: - Sistemas en los que no previéndose término de la función, el mandato es vitalicio (esencialmente EEUU y Australia). - Sistemas europeos en los que el principio de la duración ilimitada encuentra límite en la edad de los miembros, como en Austria y Bélgica, donde el mandato finaliza al cumplir los setenta años de edad. — Sistemas europeos en los cuales el periodo de mandato de los magistrados es largo: de doce años en Alemania y más frecuentemente de nueve (Italia, Francia y España).- Sistemas europeos en los que el mandato de los magistrados es breve: como Portugal y Suiza cuya duración es de seis años o Grecia en el que el periodo para los miembros que no son de derecho es de sólo dos años.

39 Se pronuncia a favor de «meditar sobre la posible conveniencia de establecer un nuevos sistema en el que los magistrados del TC ocupen su plaza hasta la edad de jubilación» y sus ventajas, entre las que se encuentra que las vacantes se producirían de forma aislada dificultando el reparto partidario, V. FERRERES COMELLA, «El Tribunal Constitucional ante la objeción democrática», en Jurisdicción constitucional y democracia, Actas de las XVI Jornadas de la Asociación de Letrados del Tribunal Constitucional, CEPC-TC, Madrid, 2011, pág. 28.

40 Conf. MORTATI, C., Istituzioni di Diritto Pubblico, Tomo II, Cedam-Padova, $8^{a}$ Ed., 1969, pág. 1241, el cual subraya que en Italia la falta de prorogatio excluye oscilaciones demasiado marcadas en la jurisprudencia. 
que el acceso al Tribunal Constitucional se convierte en la culminación de una prestigiosa carrera, a la que las presiones políticas personales posiblemente no les afectaran de la misma manera. Parece que una solución idónea sea la de fijar la edad mínima de acceso a la condición de miembro del Tribunal Constitucional en cincuenta y cinco años, de forma tal que restarían quince para llegar a la fijada para la jubilación; los mismos que prevé el ordenamiento austriaco. Un tiempo amplio pero razonable si se compara con los doce años de estancia previstos en Alemania, o los nueve de Italia, por poner como ejemplo países que fueron fuente de inspiración en la elaboración del sistema de elección de la Constitución de 1978. Contra el aumento de la edad como requisito para acceder al Tribunal Constitucional, cabría objetar, con todo, el hecho de que convierte el Tribunal en un órgano más conservador.

El sistema alemán de designación de los Magistrados del Tribunal Constitucional establece la edad de sesenta y ocho años como fecha de tope de mandato y al mismo tiempo introduce un periodo máximo de doce años de duración del mismo, y fija como edad mínima para acceder al cargo la edad de cuarenta años ${ }^{41}$. Esta combinación consigue iniciar un proceso de finalización del carácter grupal de la designación de Magistrados, es cierto que no con tanta intensidad como lo provoca fijar una fecha personal de término del mandato para cada Magistrado, y, a la vez, mantener una rotación más fluida de sus miembros y el equilibrio entre edades ${ }^{42}$.

Con la implantación de sistemas, como el apuntado, que permiten la individualización del candidato, el problema del retraso en la renovación de los Magistrados salientes pierde su significado actual. En cierta manera, y al tratarse de candidatos de consenso y no de reparto, el retraso en la designación no tendría que tener como finalidad mantener el candidato afín. No obstante, podría responder a otro tipo de motivaciones como conseguir la acumulación de vacantes en el Tribunal Constitucional o la pretensión de hacer coincidir el nombramiento de los Magistrados con la renovación de otras instituciones para, en ambos caso, proceder al reparto o intercambio (lotizzazione de los cargos públicos). Parece imposible creer que los Magistrados del tercio del Senado que debían cesar en diciembre de 2007, no lo fueran hasta enero de 2011; y que la renovación del tercio de Magistrados del Congreso de los Diputados, cuyo mandato expiró en noviembre de 2010, siga actualmente, mediados de enero de 2012, y tras haber presentado su dimisión, sin que ésta fuera aceptada por el Presidente, sin producirse ${ }^{43}$.

41 Para GARCÍA MARTÍNEZ, M. A., «¿Quis custodiet custodet?...», op. cit., pág. 15 y 16, «la fórmula más significativa a la hora de articular su teórica desvinculación política de los órganos que los designan es la de la duración del mandato». Y añade que «Las opciones para articular la finalidad que se propone pueden ser varias, sin necesidad de llegar a la fórmula del Tribunal Supremo norteamericano de magistraturas vitalicias; la exigencia de una edad mínima para poder ser nombrado magistrado de manera que tal condición se mantendría hasta la jubilación, junto con la ampliación del mandato (para evitar que el Tribunal quedase excesivamente envejecido), e incluso el establecimiento de una incompatibilidad posterior a la jubilación, son elementos que podrían repercutir favorablemente en reforzar la independencia del Tribunal Constitucional ya que los magistrados terminarían su carrera profesional en el Tribunal eludiendo así las presiones políticas personales de que pudieran ser objeto».

42 FÉRNÁNDEZ RODRÍGUEZ, J. J., La justicia constitucional..., op. cit., pág. 49, afirma, tras hacer una relación casuística de cada uno de los países sometidos a estudio, que «la edad mínima que se suele exigir, cuando se exige, es la de cuarenta años y la máxima de setenta».

43 En Italia también se han producido situaciones de retraso del Parlamento en la elección de los Magistrado de la Corte. Vid. PINARDI, R., «Prime osservazioni sul problema dei ritardi parlamentari nell'elezionie 
En cualquier caso, parece conveniente que se constitucionalice un mecanismo que evite la demora en el nombramiento de los Magistrados. La Ley Orgánica del Tribunal Constitucional (en adelante, LOTC) establece únicamente que los Magistrados «continuarán en el ejercicio de sus funciones hasta que hayan tomado posesión quienes hubieren de sucederles» (art. 17. 2), sin disponer de ningún instrumento que evite el aplazamiento sine die de las renovaciones o sanción alguna.

En Alemania, por ejemplo, transcurridos dos meses desde la expiración del mandato de los Magistrados cesantes, el Pleno del Tribunal Constitucional Federal propone, por mayoría simple, una terna si se hubiese de elegir un solo Magistrado, y el doble de los Magistrados que sea preciso elegir en caso de que éstos sean varios [art. 7 a) de la Ley reguladora del Tribunal Constitucional alemán]. Esta solución, al no ser vinculante, no garantiza completamente, como observó con acierto en su momento Jerónimo Arozamena Sierra, una solución al problema, «pues es claro que el órgano a quien corresponde la propuesta puede no aceptar los candidatos planteados por el propio Tribunal, (...) [pero] sí allana las dificultades» ${ }^{44}$.

Se ha afirmado que «[1]a experiencia contrastada confirma que no hay fórmulas alternativas satisfactorias» ${ }^{45}$. Una opción posible podría ser que fuera el Rey, en su calidad de árbitro y moderador del funcionamiento regular de las instituciones (art. 56.1 CE) ${ }^{46}$, al que correspondiese, de no producirse la renovación en el plazo de tres meses, la designación final entre una terna de Magistrados de carrera con más de veinte años de ejercicio profesional presentada por el Consejo del Poder Judicial. Esta solución obligaría a pactar el candidato idóneo, y, en su caso, a que fueran órganos independientes del Poder Legislativo y del propio Tribunal Constitucional, los que decidieran finalmente. Un plazo que se estima prudencial y que fue el mismo que se previó en el apartado primero de la disposición transitoria $1^{\text {a }}$ de la LOTC para la primera renovación ${ }^{47}$. Se debe tener en cuenta,

dei giudici della Corte Costituzionale», en La composizione della Corte Costituzionale (Situazione italiana ed esperienze straniere), Atti del Seminario di Roma del 14 de marzo 2003, a cura di ANZON, A., AZZARITTI, G., LUCIANI, M., Giappichelli Editore, Torino, 2004, págs. 223 a 230.

44 La importancia del artículo 7 a) de la Ley del Tribunal Constitucional alemán radica en su misma existencia. Es una garantía frente a las situaciones de impasse en la elección [Cfr. LECNER/ZUCK, Bundeverfassungsgerichtsgesetz, Munich, 2011, comentario al artículo 7 a), pág. 122]. Aunque el sistema trata de evitarlo, el riesgo evidente de una cooptación corporativa que esta previsión podría suponer, así como un presunto derecho del Tribunal a autocompletarse, es difícil de superar. Cfr., AROZAMENA SIERRA, J., «Organización y funcionamiento del Tribunal Constitucional: balance de quince años», en VVAA, La Jurisdicción Constitucional en España (La Ley Orgánica del Tribunal Constitucional: 1979-1994), TC-CEC, 1995, pág. 49.

45 Servicio de Estudios, Biblioteca y Documentación del Tribunal Constitucional, «Modelos de renovación personal de Tribunales Constitucionales», op. cit., pág. 224. En el citado artículo se hace referencia a las fórmulas tales como la elaborada por el sistema alemán, la previsión de «magistrados suplentes» (Austria, Ecuador, Guatemala y Turquía) o la ideada en Chile consistente en que «[s]i no hay quorum en el Tribunal y las vacantes no se cubren en el plazo de diez días, la Cortes de integrará con las personas incluidas en una lista de posibles candidatos que el propio Tribunal elabora a esos efectos cada tres años». Se advierte que «[e]n ningún modelo se contempla la posibilidad de que el retraso en la renovación se traduzca en la tácita relección de los salientes».

46 Por ejemplo, en Italia, y siendo consciente de los diferentes sistemas, el Presidente de la República designa cinco de los quince Magistrados de la Corte Constitucional.

47 Disposición transitoria «Primera. 1. Dentro de los tres meses siguientes a la fecha de entrada en vigor de la presente Ley, el Congreso de los Diputados, el Senado, el Gobierno y el Consejo General del Poder Judicial elevarán al Rey las propuestas de designación de los Magistrados del Tribunal Constitucional. Este plazo se interrumpirá para las Cámaras por el tiempo correspondiente a los periodos intersesiones». 
de la misma manera que se hizo en la citada disposición, la interrupción del plazo, para el caso de las Cámaras, por el tiempo correspondiente a los periodos entre sesiones.

En definitiva, parece que una fórmula adecuada que impida un sistema de elección de los Magistrados del Tribunal Constitucional basado en el reparto de cuotas al permitir el inicio de una progresiva renovación individualizada de sus integrantes (se mantiene el periodo de nueve años), mantenga cierto equilibrio entre edades (se propone la edad de jubilación de los Magistrados del Tribunal Supremo) y evite la demora en los nombramientos, sería la siguiente:

Los miembros del Tribunal Constitucional cesarán el día que cumplan setenta años de edad o, en su caso, tras de haber terminado el mandato de nueve años en el ejercicio del cargo desde el día de la toma de posesión, debiéndose proceder a la designación de la vacante por el órgano al que por turno correspondiese. De no proveerse la vacante en el plazo de tres meses desde el cese, el Rey procederá directamente a su designación entre una terna de Magistrados de carrera con más de veinte años de ejercicio profesional presentados el Consejo del Poder Judicial en Pleno en la forma que determine la Ley Orgánica del Poder Judicial. El plazo se interrumpirá para las Cámaras por el tiempo correspondiente a los periodos intersesiones.

\section{PROFUNDIZACIÓN EN LA OPCIÓN POR UNA DESIGNACIÓN MÁS DEMOCRÁTICA Y NO SÓLO POLÍTICA DE LOS MAGISTRADOS DEL TRIBUNAL CONSTITUCIONAL: LA REFORMA DE SU COMPOSICIÓN}

Desde el prisma de la reforma también merece una reflexión la actual composición del Tribunal Constitucional y los órganos que designan a sus miembros, porque a través de ciertas modificaciones puede profundizarse en su democratización. De la misma manera que no cabe identificar, como ya se apuntaba, «designación política» con «designación partidista», tampoco es totalmente equiparable el calificativo de «política» al de «democrática».

\section{La opción por un número impar en la composición del Tribunal Constitucional}

Incluso en ausencia de condicionamientos partidistas como resultado de la aplicación de un sistema de designación basado en el consenso individualizado del candidato, la opción por un número impar en la composición del Tribunal Constitucional se muestra más acertada $^{48}$. Equipara el valor de los votos de los integrantes del colegio y despolitiza el

48 La mayoría de doctrina se encuentra conforme con el número actual y par de miembros del Tribunal Constitucional o no entiende que un cambio sea relevante (ARAGÓN REYES, M.; DÍEZ-PICAZO, L.; GARCÍA ROCA, J.; GABALDÓN LÓPEZ, J.; LÓPEZ GUERRA, L.; PARADA VÁZQUEZ, R. y RODRÍGUEZ BEREIJO, A.), vid. "Cuestionario sobre la reforma de la LOTC», en Teoría y realidad constitucional», núm. 4, 1999, págs. 13 a 89. A favor, sin embargo, de establecer un número impar Magistrados y suprimir el voto de calidad del Presidente se pronuncia GIMENO SENDRA V. en el cuestionario referido; ÁLVAREZ CONDE, E., Curso de Derecho Constitucional, vol. II, 6a ed., op. cit., pág. 367; RODRÍGUEZ-ZAPATA PÉREZ, J., Teoría y Práctica del Derecho Constitucional, $2^{a}$ Edición, op. cit., pág. 279; y ALZAGA VILLAAMIL, O., Derecho Político Español, Ramón Areces, $4^{a}$ ed., Madrid, 2008, pág. 703. 
nombramiento de su Presidente; en este sentido se puede decir que es más democrático ${ }^{49}$. No se valora especialmente la posición de uno de sus integrantes en el ejercicio de la función jurisdiccional ${ }^{50}$, y los partidos pierden el interés por un Presidente que no ostenta, en caso de empate, voto de calidad. Si bien es cierto que no es, en puridad, el Presidente el que dirime «sino la mitad del Tribunal cualificada porque en ella se encuentra quien lo dirige ${ }^{51}$, asegurando la mayoría en tal caso, no lo es menos que la utilización del voto de calidad siempre ha producido no sólo rechazo en la opinión pública, sino también reticencias en quienes han tenido la responsabilidad de con su voto deshacer los empates ${ }^{52}$. Siempre pueden producirse situaciones en las que el Pleno o las Salas queden, por diversas razones, constituidas por un número par; no obstante, serían excepción y no la regla.

Pero: ¿Cuál parece que pueda ser el número impar de miembros más conveniente?

El artículo 150.1 del primer Anteproyecto de Constitución ${ }^{53}$ preveía una composición de once miembros nombrados por el Rey, cuatro a propuesta del Congreso por mayoría de tres quintos de sus miembros, tres a propuesta del Senado por idéntica mayoría, dos a propuesta del Gobierno y dos a propuesta del Consejo General del Poder Judicial, que fue modificada para finalmente constituir un Tribunal conformado por doce integrantes ${ }^{54}$.

49 En este sentido se pronuncia también SANTAOLALLA LÓPEZ, F., «El voto de calidad del Presidente del Tribunal Constitucional», en Revista Española de Derecho Constitucional, núm. 85, 2009, págs. 201 a 211. El citado autor afirma: «Una presidencia de un órgano colegiado parece estar más cerca de su sentido democrático cuando se limita a presidir, esto es, a dirigir, encauzar, intermediar y promover. A lo que se ha dado en llamar liderar» (pág. 209).

50 En Alemania, por ejemplo, en caso de producirse el empate se opta por la presunción de constitucionalidad de la ley sometida a control.

51 GARCÍA ROCA, J., «Cuestionario sobre la reforma de la LOTC», op. cit., pág. 23.

52 A parte de Sentencias polémicas en las que el voto de calidad ha sido determinante —una enumeración de las mismas puede verse en FERNÁNDEZ FARRERES, G., «Artículo 90», en Comentarios a la LOTC, REQUEJO PAGÉS, J. L. (Coord.), TC-BOE, pág.1365-, su uso ha sido especialmente discutido en pasada Legislatura en la que se procedió mediante la Ley Orgánica 6/2007, a la modificación del artículo 16.3 LOTC que regula el mandato del Presidente y Vicepresidente, que establece que «Si el mandato de tres años para el que fueron designados como Presidente y Vicepresidente no coincidiera con la renovación del Tribunal Constitucional, tal mandato quedará prorrogado para que finalice en el momento en que dicha renovación se produzca y tomen posesión los nuevos Magistrados». Dicha reforma, recurrida por sesenta y siete diputados del Grupo Parlamentario Popular, fue declarada constitucional por la STC 48/2008. Para RODRÍGUEZ-ZAPATA PÉREZ, J., Teoría y Práctica del Derecho Constitucional, op. cit., $2^{a}$ ed., págs. 282 y 283, la doctrina contenida en dicha Sentencia «no es aceptable» «porque la reforma de la LO 6/2007 no respeta la duración de ese mandato tres años - que establece la letra del artículo $160 \mathrm{CE}$ y, en caso de prorogatio, se sustrae al Pleno la competencia de elegir a Presidente y Vicepresidente, sin que se aduzca en dicha Sentencia ningún fin constitucional atendible que lo justifique». Además el citado autor entiende que «[e]n cualquier caso la prórroga automática caso de ser admisible-debió aplicarse sólo a las elecciones producidas estando ya en vigor el nuevo artículo 16.3 LOTC tras la reforma de la LO 6/2007, pero nunca al caso de una Presidencia elegida por el Tribunal Constitucional en junio del año 2004, bajo el imperio de una norma anterior, que no preveía un automatismo en la prórroga de su mandato, sin el concurso obligado del Pleno de un órgano constitucional supremo e independiente —en su funcionamiento- de cualesquiera poderes públicos (Rodríguez-Zapata, VVPP a los AATC 67/2010 a 73/2010, de 23 de junio)».

53 Boletín Oficial de las Cortes, núm. 44, de 5 de enero de 1978, pág. 696.

54 En O. ALZAGA VILLAAMIL, «Sobre la composición del Tribunal Constitucional», op. cit., págs. 160 a 167 y en Derecho Político Español, op. cit., págs. 702 a 704, se relatan las causas por las que la primitiva formula contenida en el art. 150.1 del primer Anteproyecto de Constitución, elaborada por la Ponencia, fue modificada. Se puede decir que fue el empeño de la UCD por reservar la propuesta de dos miembros del Tribunal Constitucional al Gobierno y de otros dos al Consejo General del Poder Judicial y el hecho de sumar un miembro 
El devenir de los hechos ha demostrado que el Tribunal puede perfectamente funcionar con el inicial número de once Magistrados ${ }^{55}$. Tras el fallecimiento del Magistrado don Roberto García Calvo el día 18 de mayo de 2008, su plaza no ha sido todavía renovada en los primeros días del año 2012.

Esta lamentable situación nos ha servido para comprobar que no es necesaria la configuración de un Tribunal integrado por quince Magistrados, como así parece que, por mimetismo con el sistema alemán (dieciséis Magistrados) o italiano (quince Magistrados), se propuso en el debate constituyente, y ha sido, también, apoyada por ciertos sectores de la doctrina ${ }^{56}$. Máxime cuando la intención del legislador orgánico, con la reforma operada por la LO 6/2007, de 24 de mayo, de reforma de la Ley Orgánica 2/1979, de 3 de octubre, del Tribunal Constitucional (en adelante, LOTC), ha sido, como explica la propia Exposición de Motivos de la Ley, conseguir la descarga de trabajo del Tribunal al reducir el conocimiento de los recursos de amparo a aquellos que cuenten con trascendencia constitucional, y reforzar la labor de la jurisdicción ordinaria en la protección de los derechos y libertades ${ }^{57}$. Es más, la nueva regulación del amparo permitiría incluso rebajar el nú-

más a los designados por el Senado para satisfacer a la izquierda y a los nacionalistas, lo que les llevó a elevar los once miembros propuestos para configurar el Tribunal Constitucional a la cantidad de doce, siendo ésta número par. El citado profesor confiesa que hasta el último momento, en su calidad de diputado constituyente de la UCD, hizo «un esfuerzo en convencer a Fernando Abril Martorell, que encabezaba el equipo negociador de la UCD», por que se buscara, «desde la misma filosofía compositiva, un acuerdo en torno a un Tribunal Constitucional dotado de quince miembros» (vid. nota 20).

55 En el sentido de conformar un Tribunal compuesto por once Magistrados vid. ARAGÓN REYES M., «El control de constitucionalidad en la Constitución española de 1978», Revista de Estudios Políticos, núm. 7, enero-febrero 1979, pág. 177, nota 12, quien explica que para mejorar la contribución del Consejo General del Poder Judicial a la formación del Tribunal y «para dotar al mismo tiempo al Tribunal de un número impar de miembros (huyendo, además, de la creación de un órgano excesivamente numeroso), quizá hubiera sido más acertado atribuir tres miembros al Congreso, tres al Senado, dos al Gobierno y tres al Consejo General del Poder Judicial». Una posición que posteriormente matiza al afirmar en «Cuestionario sobre la reforma de la LOTC, en Teoría y realidad constitucional», núm. 4, op. cit., págs. 13 a 89, que «No está mal el número de 12 Magistrados, no ofrece grandes problemas que ese número sea par (lo que permite, además, la actual organización en dos Salas)».

56 AROZAMENA SIERRA, J., «Organización y funcionamiento del Tribunal Constitucional..., op. cit., págs. 46 y 47; FERNÁNDEZ SEGADO, F., págs. 75, 78 y 94; RODRÍGUEZ-ZAPATA PÉREZ, J., Teoría y Práctica del Derecho Constitucional, $2^{a}$ Edición, op. cit., pág 279; y ÁLVAREZ CONDE, E., Curso de Derecho Constitucional, op. cit., pág. 367, quien plantea como posible un Tribunal conformado por nueve Magistrados. ALZAGA VILLAAMIL, O., «Sobre la composición del Tribunal Constitucional», op. cit., págs. 164, explica como los negociadores, entre los que se encontraba como diputado constituyente de UCD, abordaron «en diálogo amplio y franco todas las posibilidades de alcanzar un consenso en torno a un número impar algo superior al de doce consensuado en la ponencia». Principalmente hablaron de cómo podían «convenir una composición de quince miembros, pues parecía que este era el número ideal de magistrados (...) que permitiría que el Tribunal dispusiese de tres Salas dotadas de cinco miembros, un $50 \%$ más de Salas que las hoy existentes y configuradas por un número impar de miembros, frente a las Salas de seis miembros actuales, pero el hecho es que pese a dedicar lo mejor de nuestro cansancio a este empeño no nos fue posible consensuar una fórmula compositiva concreta».

57 Con la reforma del amparo el legislador orgánico apostó por la función de defensa objetiva de la Constitución que se ejerce por el Tribunal Constitucional no sólo a través del control de constitucionalidad sino también a través del nuevo recurso de amparo objetivo. El Tribunal Constitucional ha dejado de ser la tercera instancia judicial en materia de derechos y libertades fundamentales, para desempeñar su labor de máximo intérprete de la Constitución a través del conocimiento de determinados recursos de amparo que, por las causas explicitadas en la LOTC, deben ser, dada su posición de superioridad, objeto de conocimiento. Vid. 
mero de once Magistrados a nueve ${ }^{58}$. El mismo número de Magistrados que integran el Tribunal de los Estados Unidos ${ }^{59}$. En apoyo de su disminución cabe decir que la mayoría de la doctrina conviene en que cuanto mayor sea el número de Magistrados que integren el Tribunal Constitucional más se demorarán sus decisiones ${ }^{60}$.

Un Tribunal Constitucional conformado por nueve Magistrados actuaría en Pleno y en Salas. Éstas, compuestas por cuatro Magistrados y presididas por los Magistrados más antiguos, se encargarían del trámite de admisión. Desaparecen las Secciones. Su eliminación cobra sentido tras la reforma de la LOTC. No sólo por la esperada disminución de recursos de amparo, finalidad última de la reforma, sino porque, además, con la nueva regulación, el trámite de admisión adquiere una importancia equiparable a la de la decisión de fondo de la que carecía con la normativa anterior. La decisión de admisión ya no se ciñe a la constatación, en aplicación de la doctrina constitucional preexistente, de la existencia de vulneración constitucional, sino a la apreciación de la especial trascendencia del asunto que, la mayoría de las veces, responderá, por el nuevo carácter objetivo del amparo, a la necesidad de dictar doctrina o a su posible replanteamiento. Es por ello que dicha decisión, excluyente, por cuanto puede privar a la mayoría del Tribunal de un pronunciamiento de fondo con base en argumentos no estrictamente jurídicos, no debería quedar en manos de una minoría. Su trascendencia la equipara a una resolución de fondo. Por ello, parece que, incluso, en algunos asuntos, se presente conveniente que la decisión sobre la admisión se eleve al Pleno.

Las Salas se encargarían, igualmente, de resolver aquellos recursos en los que el Tribunal ejerza como garante de su propia jurisprudencia ${ }^{61}$, dejando en manos del Pleno la

GARCÍA COUSO, S., «El nuevo modelo de protección de los derechos fundamentales tras la aprobación de la LO 6/2007: la objetivación del amparo constitucional y la tutela subjetiva de los derechos por la jurisdicción ordinaria y el Tribunal Europeo de Derechos Humanos», en Revista Europea de Derechos Fundamentales, núm. 15, 2010, págs. 137 a 168.

58 ÁLVAREZ CONDE, E., Curso de Derecho Constitucional, vol. II, 6a edición, op. cit., pág. 367, plantea, junto con la proposición de un Tribunal compuesto por quince Magistrados, la posibilidad de estar conformado por nueve.

59 También se componen de nueve Magistrados los Tribunales Constitucionales de «Albania, Bosnia-Herzegovina, Eslovenia, Estonia (la Sala de control de constitucionalidad del Tribunal Supremo), Francia, Lituania, Luxemburgo, Macedonia y Rumania», vid. FERNÁNDEZ RODRÍGUEZ, J.J., La justicia..., op. cit., pág. 40. En Servicio de estudios, biblioteca y documentación del Tribunal Constitucional, «Modelos de renovación personal...», op. cit., pág. 225, se pone de manifiesto que la media de Magistrados que configuran los Tribunales Constitucionales se encuentra en torno a la citada cifra.

60 A favor un número de Magistrados no superior a los doce previstos constitucionales se han pronunciado:.VIVER PI-SUNYER, C., CRUZ VILLALÓN, P., ARAGÓN REYES, M., GIMENO SENDRA, V., VVAA, La Jurisdicción Constitucional en España (La Ley Orgánica del Tribunal Constitucional: 1979-1994), TCCEC, 1995, pág. 62 y 63.

61 En una primera aproximación a la definición del contenido de la novedosa expresión «especial trascendencia constitucional», el Tribunal en la STC 155/2009, de 25 de junio, FJ 2, ha enumerado una serie de supuestos que la definen e integran, que pueden clasificarse en cuatro grupos: «1) El integrado por los supuestos en los que el Tribunal actúa como máximo intérprete de la Constitución [supuestos a) y b)]; 2) El compuesto por los casos en los que Tribunal actúa como jurisdicción del control de la constitucionalidad de la ley [supuestos c) y d)]; 3) El integrado por aquellos supuestos en el que el Tribunal debe imponerse como órgano supremo ante el incumplimiento de su jurisprudencia [supuesto e) y f)]. 4) Y el formado por los recursos de amparo cuyos efectos trasciendan del caso concreto porque plantee una cuestión jurídica de relevante y general repercusión social o económica o tenga unas consecuencias políticas generales [supuesto g)]». Vid. GARCÍA 
resolución de los amparos en los que actuara en su calidad de máximo intérprete de la Constitución. Lo cual evitaría la disparidad de criterios. Una situación que si antes encontraba justificación en el hecho de que el recurso de amparo se ceñía a la resolución del caso en concreto, tras la reforma pierde dicho sentido pues los recursos de los que conocerá el Tribunal Constitucional serán, en aplicación de la LOTC, aquellos que se muestren necesarios para la interpretación de la Constitución o la determinación del contenido y alcance de los derechos fundamentales.

La disminución de asuntos posibilita la concentración del trabajo del Tribunal, lo cual, a su vez, propicia la configuración de una jurisprudencia sólida y sin fisuras también en materia de derechos fundamentales. En realidad, el actual recurso de amparo se ha convertido en un mecanismo más de defensa objetiva de la Constitución. Sin embargo, el legislador, con la aprobación de la LO 6/2007, optó por la desconcentración del trabajo, de manera tal que las competencias inicialmente ejercidas en exclusiva por el Pleno, han sido o pueden ser, con limitaciones, deferidas a las Salas y de las Salas a las Secciones, cuando se consideren asuntos de mera aplicación de doctrina. Seguramente buscando hacer del Tribunal un órgano más resolutivo y eficaz, pero olvidando la razón de la especial naturaleza de su composición y el elemento de unidad de órgano que debe caracterizarlo.

\section{La apuesta por una fórmula de designación más democrática de los miembros del Tribunal Constitucional}

Tras la reconducción del sistema de elección de los Magistrados del Tribunal Constitucional hacia un sistema basado en el consenso en el candidato y no en el reparto partidista de cuotas, parece conveniente profundizar más en la democratización de la elección; lo cual pasa necesariamente por el replanteamiento de los órganos encargados de la designación y del criterio de reparto de las vacantes entre ellos. Las diferentes opciones en relación con el reparto en las designaciones de los miembros del Tribunal Constitucional encuentran su justificación bien en la potenciación del significado democrático de la elección (modelo alemán, en el que todos los Magistrados son designados por las Cámaras de representación ya sea popular — Busdestag — o territorial — Bundestag — ) o en el reparto entre los diferentes Poderes del Estado (modelo italiano ${ }^{62}$ ).

La actual fórmula de designación de los Magistrados constitucionales ${ }^{63}$, de clara inspiración italiana, cabría ser modificada, con dicha intención, por una nueva que, desac-

COUSO S., «El nuevo modelo de protección de los derechos fundamentales tras la aprobación de la LO 6/2007...», op. cit., pág. 148 y 149.

62 Según el art. 135 de la Constitución italiana, de los quince magistrados que integran la Corte, un tercio son nombrados por el Presidente de la República, otra tercera parte por el Parlamento en sesión conjunta de ambas Cámaras, y el último tercio por las Magistraturas supremas ordinaria y administrativa. La composición tripartita se hace derivar de la división de los tres poderes, Cfr. PIZZORUSSO, A., «Comentario al artículo 135 de la Constitución», en Comentario della Costituzione (A cura di Giuseppe Branca), Bolonia, Zanichelli, 1981, pág. 147.

63 El art. 159.1 de la Constitución establece que «El Tribunal Constitucional se compone de doce miembros nombrados por el Rey; de ellos, cuatro a propuesta del Congreso por mayoría de tres quintos de sus miembros; cuatro a propuesta del Senado, con idéntica mayoría; dos a propuesta del Gobierno, y dos a propuesta del Consejo General del Poder Judicial». 
tivado el reparto de cuotas, potenciara la participación de las Cámaras a semejanza del modelo alemán, e hiciera desaparecer la participación del Gobierno — más propia de formas de gobierno «presidencialistas» que de sistemas, como el nuestro, «parlamentarios» — y la del Consejo General del Poder Judicial (en adelante, CGPJ).

Es posible, no obstante, una opción intermedia en la que sin anular la participación del CGPJ y del Gobierno, se reduzca su intervención. Reservar, por ejemplo, un Magistrado para que fuera designado por el Gobierno pero sometido a unos límites o restricciones. Que se eligiera entre candidatos ya propuestos por el Consejo de Estado en su calidad de máximo órgano consultivo, o el Congreso. Incluso proponer el Gobierno con el veto del Congreso. En Estados Unidos, es el Presidente el que propone sus candidatos pero éstos pueden ser vetados por el Senado. Cabría pensar además que la selección de candidatos únicamente pudiese recaer en funcionarios del grupo A con experiencia en el servicio a la Administración como Letrados del Consejo de Estado, Letrados del Tribunal Constitucional, Abogados del Estado... etc. En el caso de mantener la designación por parte del CGPJ sería conveniente plantearse la participación del Ministerio Fiscal en la designación. Pero sería preciso hacer del Ministerio Fiscal un órgano no dependiente. De hecho, como veremos, el art. 159.1 CE reconoce a los Fiscales como potenciales candidatos a formar parte del Tribunal Constitucional. Sin embargo, hasta el momento no habido ningún Magistrado que ostentara tal condición.

No parece eficaz al afecto de la democratización de la elección de los miembros del Tribunal Constitucional, resucitar la filosofía de la Constitución de 1931 que reservaba dos puestos, en el entonces denominado Tribunal de Garantías Constitucionales, a dos letrados designados por los Colegios de Abogados y a dos profesores nombrados por las Facultades de Derecho (art. 122). Opción ya rechazada en el periodo constituyente. En todo caso, quizás se muestre más conveniente ampliar la participación en la designación a otras instituciones a través de técnicas como la proposición. Por su parte, la integración de nuevos cuerpos de la Comunidad jurídica, que si bien son susceptibles constitucionalmente de designación, no han formado parte históricamente del Tribunal (Letrados, Abogados del Estado... etc.), depende, en definitiva, de los órganos que los designan.

En cuanto a la mayoría de tres quintos necesaria para la propuesta de los designados por las Cámaras parece adecuada. Una mayoría superior entorpecería el acuerdo y la mayoría simple dejaría fuera del consenso al partido en la oposición y a las minorías. Evidentemente se potencia al Grupo Parlamentario mayoritario a quien en la práctica, por contar con mayor respaldo democrático, le corresponderá la proposición del candidato, y se deja en manos del resto de los integrantes de la Cámara su confirmación. En definitiva, consenso significa «acuerdo producido por consentimiento entre todos los miembros de un grupo o entre varios grupos» ${ }^{64}$. Es de advertir como el sistema designación propuesto acaba mostrándose similar al norteamericano, pero, dado que el nuestro es parlamentario y no presidencialista, la candidatura partirá del grupo parlamentario mayoritario que, dependiendo de su posición en la Cámara, necesitaría de mayor o menor respaldo.

64 Según la definición de la RAE. 
Por último, respecto de la ampliación de la participación de las Comunidades Autónomas en la designación de los Magistrados del Tribunal Constitucional ${ }^{65}$, se hace necesaria la tan solicitada reforma del Senado para su conversión en un verdadera Cámara de representación territorial.

\section{Una nueva redacción del párrafo primero del art. 159 de la Constitución:}

En orden a lo todo expuesto podrían articularse dos propuestas de reforma del artículo 159.1 CE, si bien es la última de las planteadas la que me parece más recomendable pues potencia el carácter democrático de la elección de los miembros del Tribunal Constitucional a través, por un lado, de la exclusión de la intervención del Gobierno, y la disminución, por otro, sin anularla, de la intervención del CGPJ, en consideración a su naturaleza democrática derivada de la intervención del Parlamento en la elección de sus vocales. Modelo italiano: El Tribunal Constitucional se compone de nueve miembros nombrados por el Rey; de ellos, tres a propuesta del Congreso por mayoría de tres quintos de sus miembros; tres a propuesta del Senado, con idéntica mayoría; dos a propuesta del Consejo General del Poder Judicial (y el Ministerio Fiscal); y uno a propuesta del Gobierno (con la intervención del Congreso de los Diputados, el Consejo de Estado o el Rey). Modelo alemán: El Tribunal Constitucional se compone de nueve miembros nombrados por el Rey; de ellos, cuatro a propuesta del Congreso por mayoría de tres quintos de sus miembros; cuatro a propuesta del Senado, con idéntica mayoría; y uno a propuesta del Consejo General del Poder Judicial.

\section{LA CUALIFICACIÓN DE LOS DESIGNADOS Y SU CONTROL}

En nuestro ordenamiento, el apartado 2 del art. 159 establece que «[l]os miembros del Tribunal Constitucional deberán ser nombrados entre Magistrados y Fiscales, Profesores de Universidad, funcionarios públicos y Abogados, todos ellos juristas de reconocida competencia con más de quince años en el ejercicio profesional». Por su parte, el art. 18 LOTC señala que «[1]os miembros del Tribunal Constitucional deberán ser nombrados entre ciudadanos españoles que sean Magistrados, Fiscales, Profesores de Universidad, funcionarios públicos o Abogados, todos ellos juristas de reconocida competencia con más de quince años de ejercicio profesional o en activo en la respectiva función» (art. 18 LOTC). ¿Qué significa juristas de reconocida competencia? ¿Cómo deben computarse los quince años en el ejercicio profesional?

Parece evidente que la reconocida competencia es una cuestión a considerar por los órganos encargados constitucionalmente de su designación. Tras la reforma de la LOTC operada por la LO 6/2007, de 24 de mayo, los candidatos propuestos por el Congreso de los Diputados y el Senado deben efectuar una comparecencia ante las Comisiones parla-

$65 \mathrm{Al}$ respeto conviene recordar la reforma de art. 16.1 de la LOTC que estableció que «[1] propuestos por el Senado serán elegidos entre los candidatos presentados por las Asambleas Legislativas de las Comunidades Autónomas en los términos que determine el Reglamento de la Cámara». Precepto que tras ser recurrido fue declarado constitucional por las SSTC 49/2008, de 9 de abril, y 108/2008, de 24 de julio. 
mentarias y someterse a las preguntas de los Grupos (art. 16.2 LOTC). En este sentido, se ha propuesto por la doctrina, pero con carácter permanente, la creación de una comisión parlamentaria «que estudie, seleccione, actualice y debata sobre el curriculum vitae de los posibles candidatos futuros, a efectos de propuestas sucesivas» ${ }^{66}$, con la finalidad de poder informar a las Cámaras de los curricula de los potenciales candidatos. Esta medida parece más coherente que el de la actual comparecencia, en la que se deben exponer y debatir públicamente los méritos del candidato, pues, como pone de manifiesto Arozamena Sierra ${ }^{67}$, «este mecanismo tiene sentido en Estados Unidos porque allí el nombramiento de todos los jueces del Supremo (...) corresponde al Presidente. Es, por ello, razonable que se establezca un control por las Cámaras de un nombramiento realizado además, no se olvide, con carácter vitalicio; menos comprensible parecería, sin embargo, que las Cámaras controlasen un nombramiento que a ellas mismas corresponde pues, en definitiva, son ellas las que han de decidir si el candidato les satisface o no, y para decidir tal cosa se vota la — su - propuesta, de suerte que el control se verifica sobradamente no votando al candidato». Al que se une otro «de cariz práctico», que es que «si tal mecanismo se instituye tal vez no sea fácil encontrar muchos candidatos solventes que se arriesguen a poner en juego ante el ojo público su prestigio en un interrogatorio y debate como el apuntado».

No se muestra tan claro, sin embargo, la forma de cómputo del requisito temporal de ejercicio profesional. Precisamente la duda sobre la interpretación realizada por la Mesa del Congreso de los artículos citados que por Acuerdo de 1 de junio de 2010 no admitió a trámite la propuesta de don Enrique López y López como candidato para la elección de Magistrados del Tribunal Constitucional, llevó al Parlamento de La Rioja y a la Asamblea de la Comunidad de Madrid a plantear recurso de amparo ante el Tribunal Constitucional. Recursos que fueron finalmente inadmitidos por la falta de legitimación de los recurrentes ${ }^{68}$, por lo que no se entró a conocer sobre el fondo del asunto.

Con la finalidad de resolver los problemas interpretativos se propone distinguir claramente entre, por un lado, los quince años de ejercicio profesional requeridos para aquellos candidatos propuestos por el Congreso de los Diputados y el Senado, en los que para su cómputo se tendría en cuenta cualquier actividad que durante ese periodo de tiempo les hubiera proporcionado reconocida competencia; y, por otro, los quince años en el ejercicio de la función jurisdiccional así como su situación en activo en la carrera judicial necesarios para nombrar por el CGPJ a Jueces y Fiscales, por ser dicha situación, su pertenencia actual a la carrera judicial o fiscal, la que permite que sean nombrados por el citado órgano.

En el sentido de lo expuesto se propone la siguiente redacción del art. 159.2 CE:

Los miembros del Tribunal Constitucional propuestos por el Congreso y el Senado deberán ser nombrados entre Magistrados y Fiscales, Profesores de Universidad, funcionarios públicos y Abogados, todos ellos juristas de reconocida competencia de más de cuarenta años de edad y con más de quince años de ejercicio profesional. Los miembros propuestos por el Consejo General del Poder Ju-

66 RODRÍGUEZ-ZAPATA PÉREZ, J., Teoría y Práctica del Derecho Constitucional, $2^{a}$ Edición, op. cit., pág 279.

67 AROZAMENA SIERRA, J., «Organización y funcionamiento del Tribunal Constitucional: balance de quince años...», op. cit., págs. 49 y 50.

68 AATC 192 y 193/2010, de 1 de diciembre. 
dicial de entre Magistrados y Fiscales deberán contar con más de cuarenta años de edad y con más de quince en activo en la carrera judicial o fiscal.

\section{CONCLUSIÓN}

Con las propuestas de reforma del artículo 159 CE sugeridas en el presente trabajo, se ha pretendido, desde la confirmación del modelo de Justicia Constitucional por el que optó el constituyente de 1978, y con la intención de que con ellas se recupere el prestigio y la credibilidad del Tribunal Constitucional, perdida a consecuencia de la instrumentalización política sufrida principalmente estos últimos años, formalizar una nueva garantía que sumada a las ya establecidas para preservar la independencia e imparcialidad de sus integrantes, frene el reparto partidario de las vacantes de un órgano constitucional clave en el funcionamiento del Estado de Derecho. Como reza el título del estudio, que consiga superar la lógica del Estado de partidos en el Tribunal Constitucional.

La apuesta por la elección política, que no partidista, de sus miembros, basada en la individualización de la designación de los Magistrados como fórmula para superar la intervención de los partidos políticos, y una composición más democrática y no sólo política del Tribunal Constitucional, en la que las Cámaras, como representantes de la soberanía popular, se erigen en protagonistas de la designación, han sido los ejes sobre las que se han basado las modificaciones del citado precepto.

El resultado, una fórmula que con el inicio de una progresiva renovación individualizada de sus integrantes impida un sistema de elección de los Magistrados del Tribunal Constitucional basado en el reparto de cuotas, mantenga cierto equilibrio entre edades, evite la demora en los nombramientos y apueste por la cualificación de los designados y su control.

La solución se encuentra en la desvinculación directa de los partidos políticos en la designación a los Magistrados del Tribunal Constitucional y en la indiscutible aptitud del finalmente escogido, pues, como afirmaba Kelsen «[s]ólo desde la ingenuidad o desde la hipocresía puede pretenderse que la democracia sea posible sin partidos políticos» ${ }^{69}$. Hay que ser consciente de que «ningún sistema puede proporcionar una independencia judicial que esté más allá del bien y del mal» ${ }^{70}$. Pero, «entre la fantasiosa independencia absoluta y la sumisión ciega ante una ideología partidista seguramente hay un espacio para una forma de independencia humanamente razonable, basada en el esfuerzo por el rigor, la profundidad y la calidad de las argumentaciones constitucionales, entre las que debe incluirse la buena filosofía del Derecho» ${ }^{71}$.

$$
* * *
$$

TITLE: How to overcome the strength of political parties in the Constitutional Court: The reform of article 159 of the Spanish Constitution.

69 KELSEN, H., De la esencia y el valor de la democracia, Edición y traducción de REQUEJO PAGÉS, J.L., KRK Ediciones, Oviedo, 2006, pág. 73.

70 RUIZ MIGUEL, A., «Modelo americano y modelo europeo de Justicia constitucional», Doxa, 23, 2000, pág. 158.

71 Ibidem. 
ABSTRACT: The political positioning that the Spanish Constitutional Court has experienced during the last few years has caused a devaluation of its credit and prestige. This research considers the possibility of reforming article 159 of the Spanish Constitution and explores some reforms that, reaffirming the Constitutional model established by the Spanish Constitution of 1978, would not only avoid appointments by political parties but also make the Court a more democratic and a less political institution, aiming to overcome the strength of political parties and to strength a key institution of our constitutional system.

RESUMEN: La instrumentalización política a la que se ha visto sometido especialmente estos últimos años el Tribunal Constitucional ha deteriorado su prestigio y credibilidad. En este trabajo se reflexiona sobre la conveniencia de la reforma del art. 159 CE y se sugieren posibles modificaciones que, desde la confirmación del modelo de Justicia Constitucional por el que optó el constituyente de 1978, frenen el reparto partidario de sus vacantes y hagan de la citada institución un órgano más democrático y menos político con la finalidad de superar la lógica del Estado de partidos y revitalizar una institución clave de nuestro sistema constitucional.

KeY Words: Constitutional reform. Article 159 of the Spanish Constitution. Election of Judges. The strength of political parties. Lotizzazione.

Palabras Clave: Reforma constitucional. Artículo 159 de la Constitución española. Designación de Magistrados del Tribunal Constitucional. Estado de partidos o partidocracia. Lotizzazione.

FECHA DE RECEPCIÓN: 20.12.2011

FECHA DE ACEPTACIÓN: 15.02.2012 